05,06, 11

\title{
Структура, сегнетоэлектрические и магнитоэлектрические свойства объемных композитов $\mathrm{PZT}-\mathrm{NiFe}_{1.9} \mathrm{Co}_{0.02} \mathrm{O}_{4-\delta}$
}

\author{
(C) В.Н. Шут ${ }^{1}$, В.М. Лалетин ${ }^{1}$, С.Р. Сырцов ${ }^{1}$, В.Л. Трубловский ${ }^{1}$, Ю.В. Медведева ${ }^{1}$, \\ К.И. Янушкевич ${ }^{2}$, М.В. Бушинский ${ }^{2}$, Т.В. Петлицкая ${ }^{3}$ \\ ${ }^{1}$ Институт технической акустики НАН Беларуси, \\ Витебск, Беларусь \\ ${ }^{2}$ Научно-практический центр НАН Беларуси по материаловедению, \\ Минск, Беларусь \\ ${ }^{3}$ Интеграл, \\ Минск, Беларусь \\ E-mail: shut@vitebsk.by
}

(Поступила в Редакцию 13 марта 2018 г.)

\begin{abstract}
Исследованы фазовый состав, микроструктура, диэлектрические, сегнетоэлектрические, магнитные и магнитоэлектрические свойства объемных керамических композитов $(1-x) \mathrm{PZT}-x \mathrm{NiFe}_{1.9} \mathrm{Co}_{0.02} \mathrm{O}_{4-\delta}$ со связностью 3-0. Методами рентгеноструктурного анализа и электронной микроскопии установлено, что ферримагнитная фаза (со структурой шпинели) и сегнетоэлектрическая фаза (с тетрагональной перовскитовой структурой) раздельно сосуществует в композитах всех составов. Одновременное наличие в композитах сегнетоэлектрических и ферримагнитных свойств подтверждено посредством измерения в них $P(E)$ и $\sigma(B)$ петель гистерезиса, а также исследованием температурных зависимостей диэлектрических и магнитных свойств. Полученные композиты обладают высокими магнитоэлектрическими характеристиками: коэффициент по напряжению для состава $x=0.4$ составляет $215 \mathrm{mV} / \mathrm{A}$ на частоте $1 \mathrm{kHz}$ и $130 \mathrm{~V} / \mathrm{A}$ на частоте электромеханического резонанса, равной $380 \mathrm{kHz}$.
\end{abstract}

DOI: $10.21883 /$ FTT.2018.09.46387.065

\section{1. Введение}

В последние годы сохраняется устойчивый интерес к мультиферроикам - классу материалов, в которых сосуществуют магнитное и электрическое упорядочение $[1,2]$. Взаимодействие электрической и магнитной подсистем в этих материалах проявляется в виде магнитоэлектрического (МЭ) эффекта. Указанный эффект заключается в возникновении в образце электрического поля при приложении магнитного $-E=\alpha_{E} H$ (прямой МЭ-эффект) или магнитного поля при приложении электрического - $H=\alpha_{H} E$ (обратный МЭ-эффект). C точки зрения практического применения наиболее перспективными являются двухфазные магнитоэлектрические композиты различной связности, состоящие из двух механически связанных друг с другом фаз - магнитострикционной и пьезоэлектрической. Хотя МЭ-эффект отсутствует в отдельных фазах, в результате взаимодействия пьезоэлектрической и магнитной подсистем через упругие деформационные поля, он наблюдается в композитах - возникает как результат произведения свойств (product property) отдельных фаз структуры. Ключевыми моментами при создании МЭ-композитов являются высокие характеристики отдельных компонентов, формирование качественного интерфейса (perfect interface) между магнитной и пьезоэлектрической фазами и тип связности. Из 10 возможных типов соединения фаз в двухфазных композитах наибольшее распространение получили объемные композиты со связностью 3-0 (по классификации Newnham [3]). Их достоинством является простота технологии изготовления и механическая прочность. В качестве материалов для магнитострикционной и пьезоэлектрической фаз чаще всего используются, соответственно, различные ферриты и сегнетоэлектрические перовскиты (в основном цирконаттитанат свинца (PZT) различных модификаций) [1].

Функционирование МЭ-элементов в составе различных электронных устройств предъявляет повышенные требования к их „традиционным“ электрофизическим характеристикам - величинам диэлектрических потерь, диэлектрической и магнитной проницаемостей, удельного сопротивлению и т.д. Полевые, концентрационные и температурные зависимости этих параметров оказывают значительное влияние на свойства магнитоэлектриков и требует отдельного рассмотрения. Кроме того, несомненный интерес представляет изучение взаимного влияния фаз на особенности проявления сегнетоэлектрической и магнитной неустойчивости в магнитоэлектрических композитах [4-6].

Целью данной работы является исследование структуры, электрофизических, сегнетоэлектрических, магнитных и магнитоэлектричекких свойств объемных 3-0 композитов составов $(1-x) \mathrm{PZT}-x \mathrm{NiFe}_{1.9} \mathrm{Co}_{0.02} \mathrm{O}_{4-\delta} \quad$ в диапазоне температур $20-450^{\circ} \mathrm{C}$.

\section{2. Образцы и методика эксперимента}

Объектом исследования в данной работе являлся МЭ керамический композит состава 
$(1-x) \mathrm{PZT}-x \mathrm{NiFe}_{1.9} \mathrm{Co}_{0.02} \mathrm{O}_{4-\delta} \quad$ (где $\quad x=0.1-0.9 \quad$ весовых долей (weight fraction)) со связностью 3-0, при которой частицы феррита никеля распределены в матрице сегнетоэлектрического (пьезоэлектрического) цирконат-титаната свинца. Выбор феррита никеля в качестве магнитной составляющей обусловлен его высокими магнитострикционными параметрами и низким коэрцитивным полем. Данный материал по своим электрическим свойствам относится к классу полупроводников с контролируемой валентностью. Несмотря на ионный характер химической связи, в ферритах преобладает электронная проводимость, обусловленная переходами электронов между разновалентными ионами железа, находящимися в эквивалентных октаэдрических позициях шпинельной решетки - $\mathrm{Fe}^{2+}\left(3 d^{6}\right) \leftrightarrow \mathrm{Fe}^{3+}\left(3 d^{5}\right)$ (механизм Вервея-де Бура [7]). Слабосвязанные с $\mathrm{Fe}^{2+}$ электроны определяют основные электрические свойства ферритов, а величина проводимости находится в прямой зависимости от концентрации ионов $\mathrm{Fe}^{2+}$. Известно, что высокая проводимость магнитной фазы делает невозможным поляризацию образца и получение высоких МЭ-характеристик. Поддержание ионов в трехвалентном состоянии $\mathrm{Fe}^{3+}$, обеспечивающее повышение удельного сопротивления феррита, достигалось за счет изменения стехиометрии и добавки $2 \%$ кобальта. В нашем случае образцы феррита $\mathrm{NiFe}_{1.9} \mathrm{Co}_{0.02} \mathrm{O}_{4-\delta}$ имели удельное сопротивление $\rho_{20}{ }^{\circ} \mathrm{C} \sim 10^{10} \Omega \cdot \mathrm{cm}$.

Используемая в данной работе промышленная пьезоактивная керамика (PZT) представляет собой сегнетоэлектрический материал (температура Кюри $\left.T_{c}=365^{\circ} \mathrm{C}\right)$ с высокими диэлектрическими $\left(\varepsilon \sim 10^{3}\right.$, $\operatorname{tg} \delta \sim 0.01$ при $\left.20^{\circ} \mathrm{C}\right)$, пьезоэлектрическими $\left(d_{33} \approx\right.$ $\left.\approx 280 \cdot 10^{-12} \mathrm{C} / \mathrm{N}\right)$ характеристиками и низкой проводимостью $\left(\rho_{20}{ }^{\circ} \mathrm{C}=10^{12} \Omega \cdot \mathrm{cm}\right)$. Отметим, что приведенные выше параметры для материалов обеих фаз композита характерны для случаев их раздельного изготовления по оптимальным для них технологическим режимам. В случае же совместного изготовления, их индивидуальные характеристики в составе композита могут отличаться от „табличных“, а эффект „суммы свойств“" (sum properties) может не выполняться.

Объемные композиты изготовлены путем спекания смесей однофазных компонентов. Образцы системы $(1-x) \mathrm{PZT}-x \mathrm{NiFe}_{1.9} \mathrm{Co}_{0.02} \mathrm{O}_{4-\delta} \mathrm{c}$ содержанием феррита $0.1,0.2,0.3,0.4,0.5,0.6,0.7,0.8$ и 0.9 весовых долей спекались в тиглях со свинецсодержащей засыпкой в течение двух $\mathrm{h}$ при температуре $1240^{\circ} \mathrm{C}$. Скорость охлаждения образцов не превышала $50^{\circ} \mathrm{C} / \mathrm{h}$. Образцы имели форму дисков диаметром 8.7-8.8 mm и толщиной 0.8-0.9 mm. Электроды наносили вжиганием серебряной пасты при температуре $650^{\circ} \mathrm{C}$ в течение $20 \mathrm{~min}$. Поляризацию материалов осуществляли при температуре $70-100^{\circ} \mathrm{C}$ в течение двух $\mathrm{h}$ в электрическом поле $4 \mathrm{kV} / \mathrm{mm}$ с последующим охлаждением в поле до комнатной температуры.

Исследования диэлектрической проницаемости $(\varepsilon)$ и тангенса угла диэлектрических потерь $(\operatorname{tg} \delta)$ проводили с использованием универсального LCR-моста
E7-8 (на частоте $1 \mathrm{kHz}$ ). Кристаллическую структуру и фазовый состав определяли на основании данных, полученных при комнатной температуре с помощью рентгеновского дифракционного анализа с использованием $\mathrm{Fe} K_{\alpha}$-излучения $(\lambda=1.9374 \AA)$. Исследование микроструктуры выполнено на сканирующем электронном микроскопе высокого разрешения S-4800 (Hitachi). Определение остаточной поляризации $P_{r}$ и величины коэрцитивного поля $E_{k}$ проводили путем исследования петель гистерезиса на частоте $50 \mathrm{~Hz}$ при комнатной температуре (модифицированная схема Sawyer-Tower). Петли магнитного гистерезиса $\sigma(B)$ изучены при помощи автоматизированного вибрационного магнитометра фирмы Cryogenic Limited. Измерения удельной намагниченности осуществлены пондеромоторным методом. МЭ-эффект исследовали путем измерения напряжения, возникающего на образце при воздействии на него переменного и постоянного магнитных полей. Эксперименты были проведены при двух различных ориентациях образцов. В одном случае вектор электрической поляризации был перпендикулярен постоянному и переменному магнитным полям (поперечный эффект), в другом случае параллелен (продольный эффект).

\section{3. Результаты эксперимента и их обсуждение}

Результаты дифракционного анализа композитов различных составов и чистых исходных компонентов представлены на рис. 1. Они свидетельствуют о том, что используемая в настоящей работе технология позволяет получать двухфазные структуры: ферримагнитная фаза $\mathrm{NiFe}_{1.9} \mathrm{Co}_{0.02} \mathrm{O}_{4-\delta}$ (со структурой шпинели) и сегнетоэлектрическая фаза PZT (с тетрагональной перовскитовой структурой) раздельно сосуществует в композитах всех составов. Других промежуточных или межграничных фаз с помощью рентгеновского дифракционного

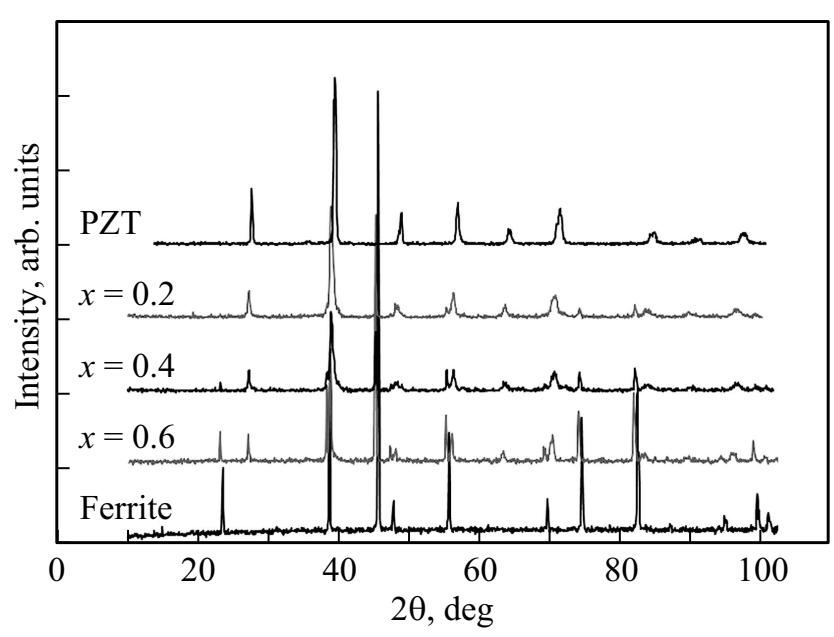

Рис. 1. Дифрактограммы композитов $(1-x) \mathrm{PZT}-x \mathrm{NiFe}_{1.9}$ $\mathrm{Co}_{0.02} \mathrm{O}_{4-\delta}$. 

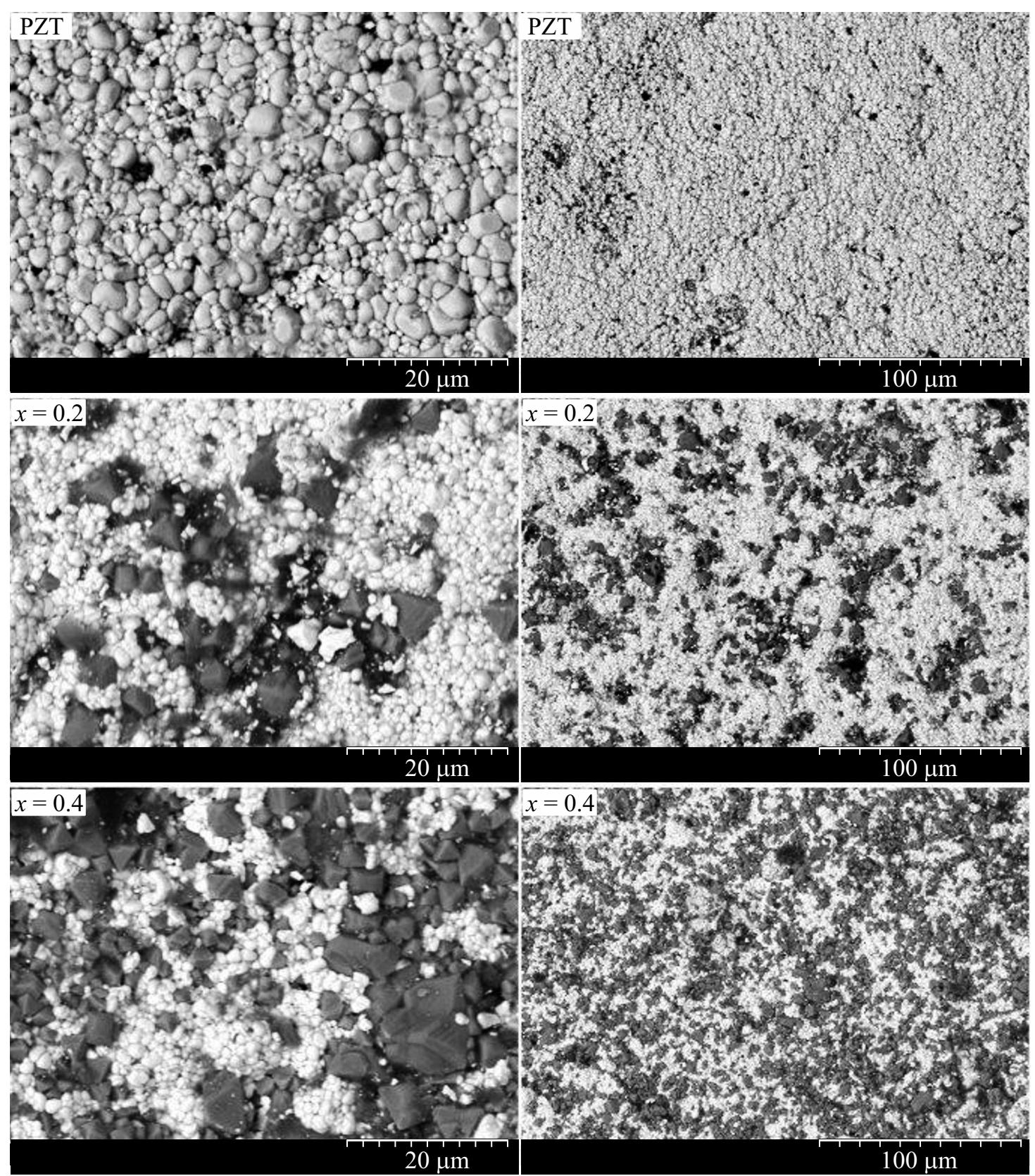

Рис. 2. SEM-изображения керамики PZT и композитов различных составов (светлые зерна - PZT, темные зерна — феррит).

анализа обнаружено не было. Из дифрактограмм следует, что интенсивности пиков, соответствующих ферритной фазе, увеличиваются с ростом ее концентрации в композите. Данные электронной микроскопии подтвердили получение двухфазного композита со связностью (3-0). На рис. 2 представлены SЕМ-изображения образцов с различным содержанием ферритовой фазы при различном увеличении (черный цвет имеют кристаллиты ферритовой фазы, белый - зерна PZT). Образцы имеют достаточно однородную структуру, в которой ферритовая фаза диспергирована в матрице цирконаттитаната свинца. Однако, как видно из микрофотографий с бо́льшим увеличением, имеются заметные локаль- ные неоднородности в распределении фаз. Кроме того, с ростом содержания $\mathrm{NiFe}_{1.9} \mathrm{Co}_{0.02} \mathrm{O}_{4-\delta}$ увеличивается разброс в размерах зерен феррита. Размер зерен РZT в составе композита меньше в сравнении с „чистой пъезокерамикой.

Соединения с решетками типа перовскита (PZT) и обращенной шпинели (феррит никеля) весьма склонны к захвату чужеродных ионов с образованием твердых растворов [8]. Кроме того, близость ионных радиусов катионов, ответственных за сегнетоэлектрическое и магнитное упорядочения в фазах $-r\left(\mathrm{Ti}^{4+}\right)=60.5 \AA$, $r\left(\mathrm{Fe}^{3+}\right)=64.5 \AA, r\left(\mathrm{Ni}^{2+}\right)=69 \AA$ (при координационном числе 6) [9], способствует их взаимодиффузии и вза- 
имозамещению. Это может приводить к модификации электрофизических, сегнетоэлектрических и магнитных свойств обеих фаз композита. Наиболее сильные изменения следует ожидать в характеристиках PZT-фазы в результате ее легирования катионами $\mathrm{Fe}^{3+}$ [8]. Интенсивное внедрение таких ионов на $B$-позиции перовскитовой $A B \mathrm{O}_{3}$-структуры подтверждено экспериментально, в частности, методом энергодисперсионной рентгеновской спектроскопии [10]. С этим согласуются результаты наших рентгеновских исследований. Внедрение бо́льших по размерам катионов $\mathrm{Fe}^{3+}$ на позиции $\mathrm{Ti}^{4+}$ в решетке PZT приводит к сдвигу пиков в сторону меньших углов, что свидетельствует об увеличении размеров элементарной ячейки фазы PZT в составе композита. Ионы $\mathrm{Fe}^{3+}$, расположенные на позиции титана в решетке PZT, являются акцепторной примесью - их заряд меньше заряда замещаемых ионов $\mathrm{Ti}^{4+}$. Основным механизмом компенсации вносимого при этом дополнительного отрицательного заряда является создание вакансий кислорода $V_{\mathrm{O}}^{* *}$. Будучи наиболее подвижными дефектами, вакансии $V_{\mathrm{O}}^{* *}$ являются доминирующими носителями заряда в керамических оксидах. Именно они определяют электрофизические характеристики керамики и их изменение со временем (т. е. процессы старения) [8].

В свою очередь, в процессе спекания композита возможно внедрение ионов $\mathrm{Ti}^{4+}$ (или $\mathrm{Zr}^{4+}$ ) на позиции $\mathrm{Fe}^{3+}$ и $\mathrm{Ni}^{2+}$ в шпинельной решетке феррита. Избыточный положительный заряд, вносимый в решетку при такой замене, должен уравновешиваться созданием катионных вакансий или изменением оксидного состояния катионов, в частности, появлением ионов $\mathrm{Fe}^{2+}$. Возникновение последних может приводить к значительному изменению электрофизических характеристик магнитной фазы. Известно, что из-за особенностей электронной структуры, ферриты, помимо сильного магнитного отклика, могут проявлять необычные диэлектрические свойства (особенно в области низких частот электрического поля) $[11,12]$. Обмен электронов между ионами железа разной валентности в феррите эквивалентен обмену местами этих ионов. При этом магнитная фаза приобретает свойства, присущие полярному материалу. В случае приложения внешнего электрического поля происходят переходы электронов преимущественно вдоль направления поля. Ориентационная поляризация диполей $\mathrm{Fe}^{2+} \leftrightarrow \mathrm{Fe}^{3+}$ в области низких частот может давать существенный вклад в значение диэлектрической проницаемости феррита и соответственно всего композита. В ряде случаев он может даже превышать вклад от сегнетоэлектрической компоненты композита $[6,11,13]$.

Повышенная концентрация указанных выше дефектов в области границы раздела фаз приводит к росту влияния интерфейсных релаксационных процессов. Известно, что интегральные диэлектрические характеристики композитов определяются как свойствами фаз, так и максвеллвагнеровскими поляризационными процессами на межфазных границах (interfacial polarization) $[12,14,15]$.
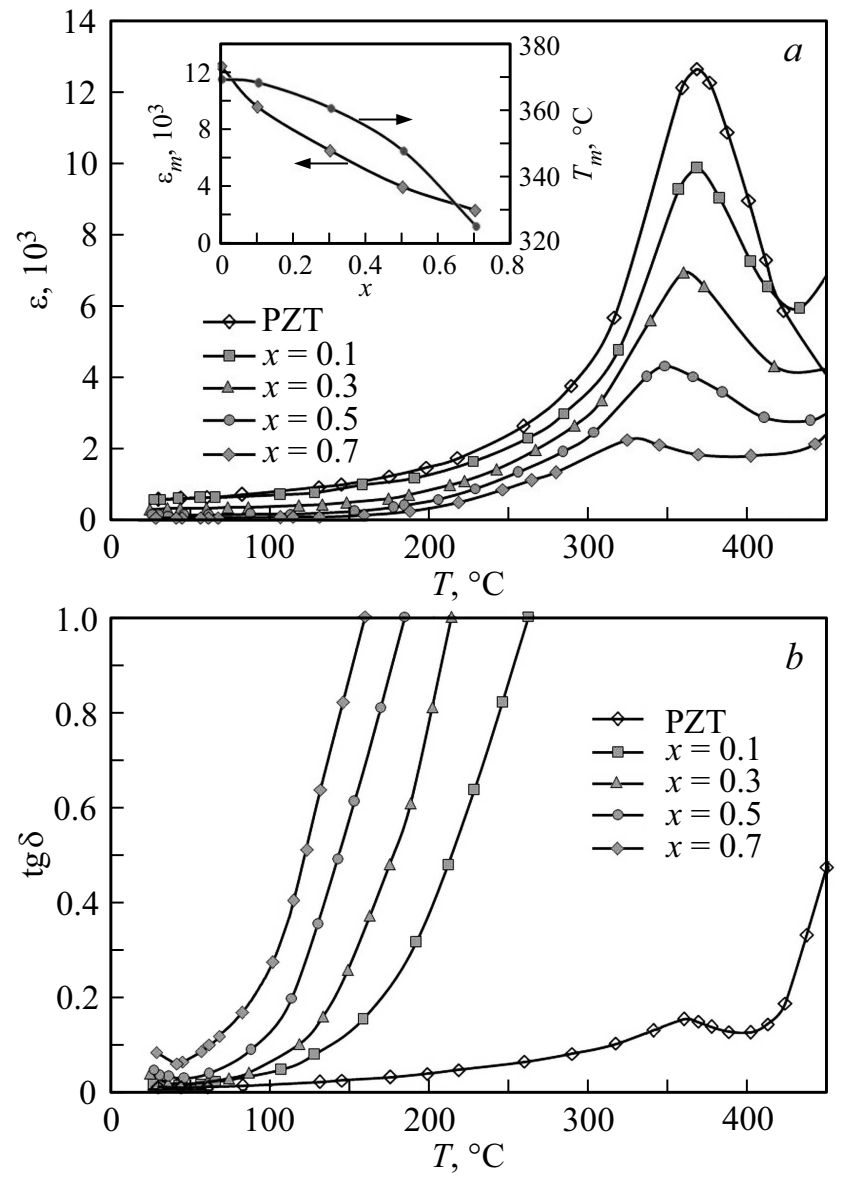

Рис. 3. Температурная зависимость диэлектрической проницаемости $(a)$ и тангенса угла диэлектрических потерь $(b)$ композитов $(1-x) \mathrm{PZT}-x \mathrm{NiFe}_{1.9} \mathrm{Co}_{0.02} 2 \mathrm{O}_{4-\delta}$.

На рис. 3 представлены температурные зависимости диэлектрической проницаемости $(\varepsilon)$ и тангенса угла потерь $(\operatorname{tg} \delta)$ композитов различных составов в диапазоне температур $20-450^{\circ} \mathrm{C}$. При изменении содержания магнитной компоненты в образцах сохраняются свойственные сегнетоэлектрической фазе PZT температурные аномалии $\varepsilon$ в области сегнетоэлектрического фазового перехода. Это свидетельствует о сохранении в материалах сегнетоэлектрической неустойчивости. Замена ионами $\mathrm{Fe}^{3+}$ части катионов $\mathrm{Ti}^{4+}$ в кислородном октаэдре перовскитовой решетки PZT (ответственных за сегнетоэлектрическую активность) приводит к „разбавлению“ (dilution effect) сегнетоэлектрических характеристик. Рост концентрации феррита способствует увеличению степени размытия сегнетоэлектрического фазового перехода. При этом температура $T_{m}$ („температура Кюри“ композита), соответствующая максимуму $\varepsilon_{m}$, снижается по сравнению с температурой фазового перехода $\left(T_{c}=365^{\circ} \mathrm{C}\right)$ в „чистой“ сегнетоэлектрической компоненте (вставка на рис. 3, $a$ ). Такие особенности диффузного фазового перехода могут быть объяснены структурным разупорядочением и флуктуацией состава в приповерхностных слоях сегнетоэлектрических зерен, 


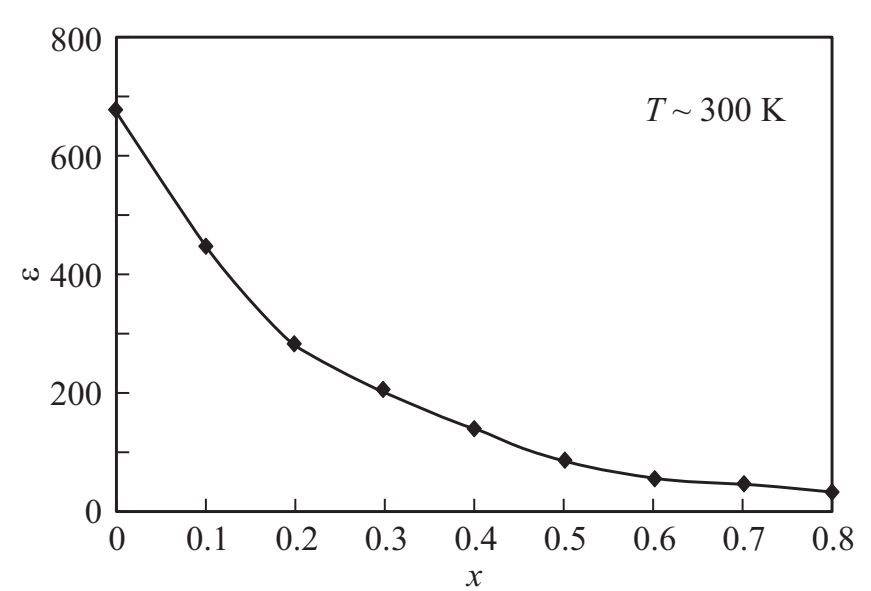

Рис. 4. Зависимость диэлектрической проницаемости композитов от содержания феррита при комнатной температуре.

возникающими в результате внедрения ионов $\mathrm{Fe}^{3+}$ в перовскитовую решетку PZT в процессе спекания $[6,12,16]$. Разбавление сегнетоэлектрической РZТ-керамики магнитной фазой приводит к уменьшению $\varepsilon$ композита практически во всем исследуемом диапазоне температуры (изменение величины $\varepsilon_{m}$ также представлено на вставке рис. $3, a)$.

График зависимости диэлектрической проницаемости композита при комнатной температуре $\left(20^{\circ} \mathrm{C}\right)$ от концентрации феррита приведен на рис. 4. Из него видно, что диэлектрическая проницаемость композита уменьшается от $\varepsilon \approx 420(x=0.1)$ до $\varepsilon \approx 40(x=0.8)$, причем наиболее существенное изменение происходит при низких концентрациях феррита (до 30 wt.\%). Можно предположить, что наблюдаемое уменьшение $\varepsilon$ связано не с ослаблением сегнетоэлектрических свойств PZTфазы в композите, а является результатом разбавления сегнетоэлектрической матрицы несегнетоэлектрическими компонентами (ферритом) [12]. Количественные детали этого эффекта неплохо описываются в рамках модели эффективной среды, развитой для сегнетоферримагнитных композитов [17].

При высоких температурах подвижность зарядов в феррите значительно возрастает. Как было отмечено выше, вследствие этого резко увеличивается вклад в поляризационные характеристики композита как самой магнитной фазы, так и релаксационных максвелл-вагнеровских процессов на межфазных границах. Из рис. 3, $a$ видно, что уже при относительно небольшой концентрации феррита $(x=0.1)$ диэлектрическая проницаемость композита при $T>400^{\circ} \mathrm{C}$ начинает превосходить $\varepsilon$ „чистой“ сегнетоэлектрической керамики PZT.

Повышенные флуктуации локальных электрических свойств, присущие МЭ-керамикам, способствуют снижению энергий активации проводимости и процессов диэлектрической релаксации. Очевидно, что с увеличением содержания магнитной фазы эти эффекты должны усиливаться, приводя к росту диэлектрических потерь в композите. Как следует из рис. $3, b$, диэлектрические потери в композите монотонно увеличиваются с ростом концентрации ферритовой фазы. Следует отметить, что при концентрациях менее $40 \mathrm{wt} \%$ потери в практически важном диапазоне температур $20-80^{\circ} \mathrm{C}$ находятся на удовлетворительно низком уровне $(\operatorname{tg} \delta \leq 0.05)$. Существенный рост $\operatorname{tg} \delta$ при концентрации магнитной фазы свыше 50 wt.\% связан с высокими потерями в $\mathrm{NiFe}_{1.9} \mathrm{Co}_{0.02} \mathrm{O}_{4-\delta}$. Возрастание диэлектрических потерь с ростом температуры для всех исследуемых составов $(x=0.1-0.9)$ вызвано увеличением проводимости в обеих компонентах системы.

Несмотря на ряд общих феноменологических свойств сегнетоэлектриков и ферритов (существование спонтанной поляризации и намагниченности ниже критической температуры, наличие петель гистерезиса $P(E)$ и $\sigma(H)$, нелинейности диэлектрической $\varepsilon(E)$ и магнитной $\mu(H)$ проницаемостей и т.п.), физические причины, лежащие в их основе, существенно различаются для обоих типов материалов. Для магнетиков характерны короткодействующие сильные взаимодействия (обменного типа). Сегнетоэлектрическая неустойчивость определяется дальнодействующими дипольными силами. В случае появления в процессе спекания в ферритсегнетоэлектрическом композите различных заряженных и дипольных дефектов именно дальнодействующие взаимодействия должны претерпевать наибольшие изменения. Исследования различных Fе-дефектных перовскитовых структур методом электронного парамагнитного резонанса показали присутствие в них различных дипольных дефектных комплексов - как заряженных $\left(\mathrm{Fe}_{\mathrm{Ti}, \mathrm{Zr}}^{\prime}-V_{\mathrm{O}}^{* *}\right)^{*}$, так и нейтральных $\left(2 \mathrm{Fe}_{\mathrm{Zr}, \mathrm{Ti}}^{\prime}-V_{\mathrm{O}}^{* *}\right)[8,18]$. Такие дефектные комплексы оказывают стабилизирующее влияние на поляризационное состояние решетки в своей окрестности и создают внутренние электрические и деформационные поля, влияющие на проводимость и процессы переполяризации.

Эффективным способом изучения сегнето- и ферримагнитной неустойчивости материала является экспериментальное исследование петель гистерезиса: намагниченность - магнитное поле $(\sigma-H)$ и поляризация - электрическое поле $(P-E)$. Типичные $P-E$-петли гистерезиса для нескольких концентраций феррита в композите представлены на рис. 5. Получение более „насыщенных“ петель (при напряженностях электрического поля выше $3 \mathrm{kV} / \mathrm{mm}$ ) невозможно из-за высокой вероятности пробоя образцов.

Из вида петель гистерезиса следует, что исследуемые материалы демонстрируют сегнетоэлектрическое поведение, характерное для фазы PZT, „разбавленной“ несегнетоэлектрическим соединением (ферритом). Свидетельством такого „разбавления“ сегнетоэлектрических свойств является уменьшение величин спонтанной $\left(P_{s}\right)$ и остаточной $\left(P_{r}\right)$ поляризаций. С увеличением содержания $\mathrm{NiFe}_{1.9} \mathrm{Co}_{0.02} \mathrm{O}_{4-\delta}$ остаточная поляризации $P_{r}$ немонотонно уменьшается от $1.64 \mu \mathrm{C} / \mathrm{cm}^{2} \quad(x=0.1)$ до $0.03 \mu \mathrm{C} / \mathrm{cm}^{2}(x=0.8)$. Причем зависимость $P_{r}$ от концентрации феррита в композите носит сильно выраженный нелинейный характер - наиболее сильное 


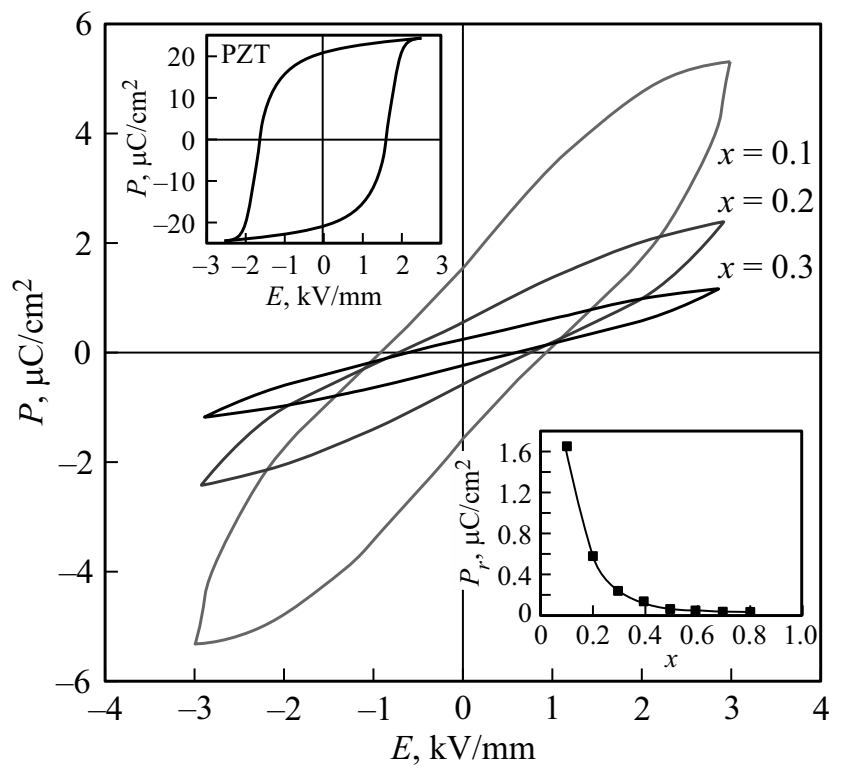

Рис. 5. Петли гистерезиса $P(E)$ композитов $(1-x) \mathrm{PZT}-x \mathrm{NiFe}_{1.9} \mathrm{Co}_{0.02} \mathrm{O}_{4-\delta}$.

изменение поляризации происходит при $x<0.2$ (нижняя вставка на рис. 5). Отметим, что коэрцитивное поле $E_{k}$ снижается существенно меньше, соответственно с $0.85 \mathrm{kV} / \mathrm{mm}(x=0.1)$ до $0.44 \mathrm{kV} / \mathrm{mm} \quad(x=0.8)$. $\mathrm{C}$ ростом количества ферритовой фазы наблюдается уменьшение площади петель гистерезиса, указывающее на снижение переполяризационных потерь. При этом уменьшается „степень прямоугольности“ петель, что свидетельствует об увеличении неоднородности образцов по составу и размерам зерен. Наблюдаемое уменьшение наклона петель $P(E)$ с увеличением содержания феррита является характерным свойством керамических материалов, в которых сегнетоэлектрические зерна окружены „пассивными“ прослойками с низкой диэлектрической проницаемостью [19]. Симметрия петель гистерезиса по обеим осям свидетельствует об отсутствии в композите внутренних электрических полей, часто возникающих в неоднородных по составу структурах [20,21]. Заметим, что использование в данной работе $\mathrm{NiFe}_{1.9} \mathrm{Co}_{0.02} \mathrm{O}_{4-\delta}$ с повышенным удельным сопротивлением $\left(\rho_{20}{ }^{\circ} \mathrm{C} \sim 10^{10} \Omega \cdot \mathrm{cm}\right)$ позволило существенно уменьшить отрицательное влияние эффекта перколяции и исследовать поляризационные характеристики композитов с повышенным содержанием ферритовой фазы (более 50 wt.\%) при высоких напряженностях электрического поля.

На рис. 6 представлены петли магнитного гистерезиса $\sigma(B)$ для композитных образцов с различной концентрацией ферритовой фазы. Вид петель подтверждает наличие в системе упорядоченных структур, вызывающих сильную намагниченность (имеющую почти безгистерезисный характер), высокую начальную магнитную проницаемость и низкое значение поля насыщения. Это свидетельствует о том, что аналогично чистому ферриту
$\mathrm{NiFe}_{1.9} \mathrm{Co}_{0.02} \mathrm{O}_{4-\delta}$ спонтанная намагниченность в МЭкерамике носит ферримагнитный характер и возникает в результате обменного взаимодействия разкомпенсированных спинов.

Магнитные свойства феррита определяются короткодействующими обменными взаимодействиями. Каждая частица феррита в композите действует как независимый центр намагничивания, а намагниченность всего образца определяется как векторная сумма этих индивидуальных вкладов. Следовательно, намагниченность образца должна изменяться пропорционально концентрации фазы феррита. Как видно из рис. 6, намагниченность насыщения $\sigma_{s}$ практически линейно увеличивается с ростом массовой доли феррита в композите соответственно от $4 \mathrm{~A} \cdot \mathrm{m}^{2} \cdot \mathrm{kg}^{-1}(x=0.1)$ до $17 \mathrm{~A} \cdot \mathrm{m}^{2} \cdot \mathrm{kg}^{-1}(x=0.4)$.

Изучение температурного поведения $\sigma=f(T)$ показало устойчивость удельной намагниченности образцов к прогреву до температуры $820 \mathrm{~K}$. В режимах измерений „нагрев“ и „охлаждение“ зависимости практически идентичны (рис. 7). С уменьшением содержания фазы $\mathrm{NiFe}_{1.9} \mathrm{Co}_{0.02} \mathrm{O}_{4-\delta}$ от 40 до $10 \mathrm{wt} \%$ наблюдается снижение как удельной намагниченности (для температуры жидкого азота от $\sim 19.5$ до $\sim 4.6 \mathrm{~A} \cdot \mathrm{m}^{2} \cdot \mathrm{kg}^{-1}$ ), так и температуры фазового превращения „магнитный порядок-магнитный беспорядок“ (от $T_{c}=795$ до $T_{c}=715 \mathrm{~K}$ ). Такое уменьшение $T_{c}$ может быть объяснено интенсификацией процесса внедрения немагнитных ионов $\mathrm{Ti}^{4+}\left(\mathrm{Zr}^{4+}\right)$ в октаэдрические $B$-позиции обращен-

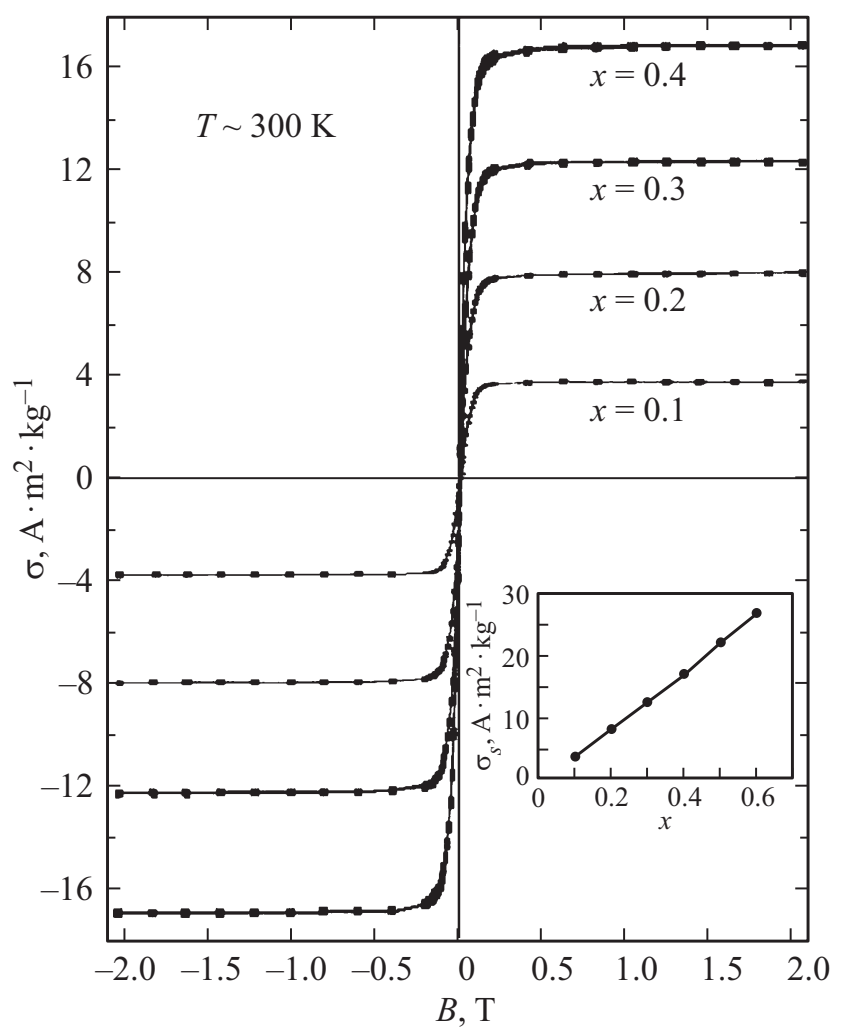

Рис. 6. Магнитные петли гистерезиса $\sigma(B)$ композитов с различным содержанием феррита. 

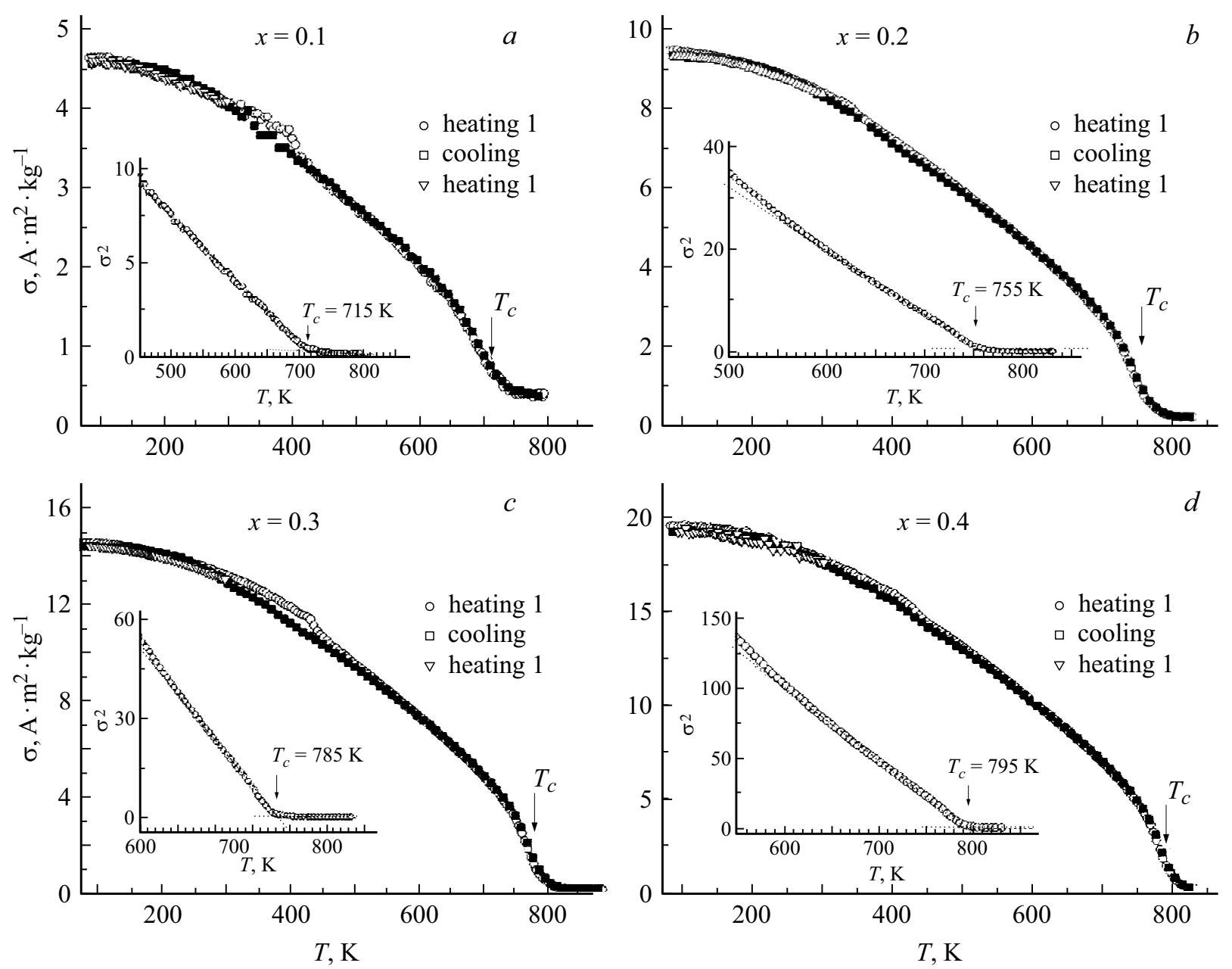

Рис. 7. Температурные зависимости удельной намагниченности композитов.

ной шпинельной решетки феррита с ростом концентрации PZT. При этом увеличение расстояния между магнитными моментами в $A$ - и $B$-подрешетках приводит к ослаблению косвенного обменного А-О-В взаимодействия, ответственного за ферримагнитное упорядочение в системе [22]. Следует отметить, что размер зерна феррита также может влиять на магнитные свойства и температуру Кюри [23]. Однако данные электронной микроскопии для наших образцов указывают, что этот фактор не является определяющим (размеры кристаллитов феррита изменяются незначительно).

Как продольный, так и поперечный МЭ-коэффициенты композитов возрастают с увеличением концентрации феррита (рис. 8). Максимальными характеристиками обладали образцы с содержанием $40 \mathrm{wt} . \%$ $\mathrm{NiFe}_{1.9} \mathrm{Co}_{0.02} \mathrm{O}_{4-\delta}$, при котором обеспечивается наилучшее взаимодействие магнитной и пъезоэлектрической подсистем [24]. Дальнейший рост массовой доли феррита приводит к снижению магнитоэлектрических характеристик.

Полевая зависимость МЭ-коэффициента по напряжению для образца состава 0.6PZT42$0.4 \mathrm{NiFe}_{1.9} \mathrm{Co}_{0.02} \mathrm{O}_{4-\delta}$, демонстрирующего максимальный
МЭ-сигнал при продольном и поперечном эффектах, представлена на рис. 9. В случае продольного эффекта (кривая 1) МЭ-коэффициент по напряжению достигает максимальной величины $215 \mathrm{mV} / \mathrm{A} \quad$ в магнитном

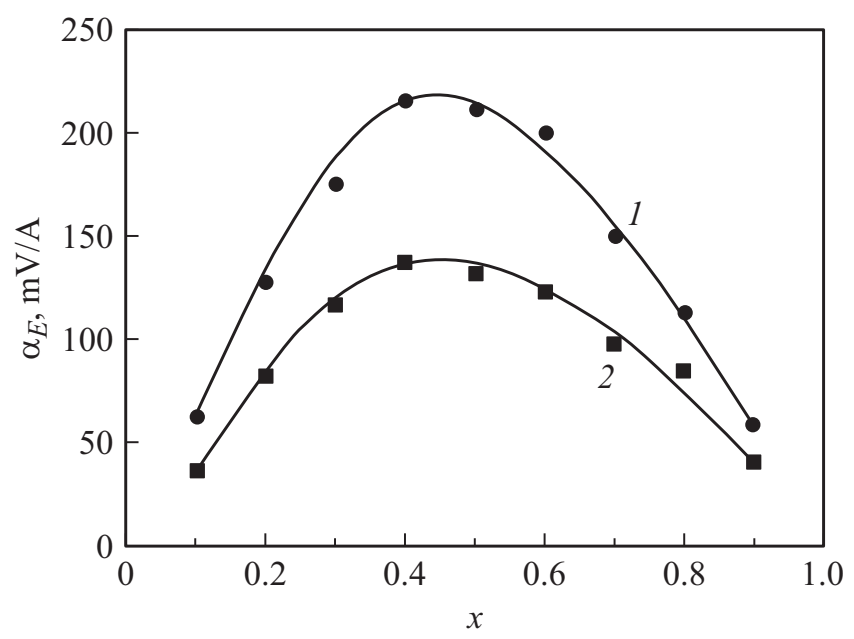

Рис. 8. Зависимости продольного (1) и поперечного (2) МЭ-коэффициентов по напряжению от состава керамики. 


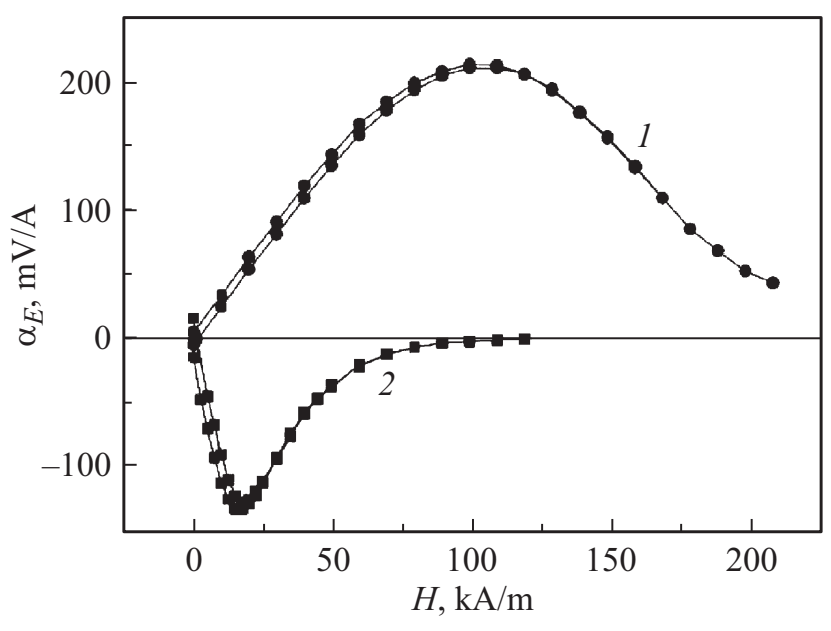

Рис. 9. Полевая зависимость продольного (1) и поперечного (2) МЭ-коэффициентов (на частоте $1 \mathrm{kHz}$ ) для композита $0.6 \mathrm{PZT}-0.4 \mathrm{NiFe}_{1.9} \mathrm{Co}_{0.02} \mathrm{O}_{4-\delta}$.

поле, равным $100 \mathrm{kA} / \mathrm{m}$. В случае поперечного эффекта (кривая 2) коэффициент по напряжению принимает максимальное значение $137 \mathrm{mV} / \mathrm{A}$ при $16 \mathrm{kA} / \mathrm{m}$. Магнитоэлектрический сигнал на частоте электромеханического резонанса $380 \mathrm{kHz}$ в композите данного состава превышает низкочастотный на три порядка и достигает $130 \mathrm{~V} / \mathrm{A}$. Полевые зависимости МЭ-коэффициентов, полученные для образцов других составов, имеют аналогичный вид, отличающийся величиной сигнала и значением подмагничивающего поля.

\section{4. Заключение}

$\begin{array}{cccr}\text { C } & \text { использованием } & \text { керамической } & \text { техно- } \\ \text { логии } & \text { изготовлены } & \text { объемные } & \text { композиты }\end{array}$
$(1-x) \mathrm{PZT}-x \mathrm{NiFe}_{1.9} \mathrm{Co}_{0.02} \mathrm{O}_{4-\delta} \quad(x=0.1-0.9) \quad$ со связностью 3-0. Методами рентгеноструктурного анализа и электронной микроскопии подтверждено, что используемая технология позволяет получать двухфазные композиты, состоящие из ферримагнитной фазы $\mathrm{NiFe}_{1.9} \mathrm{Co}_{0.02} \mathrm{O}_{4-\delta}$ (со структурой шпинели) и сегнетоэлектрической фазы PZT (с тетрагональной перовскитной структурой).

Изучены диэлектрические, сегнетоэлектрические, магнитные и магнитоэлектрические свойства образцов в зависимости от концентрации феррита. Одновременное наличие сегнетоэлектрических и ферримагнитных свойств в композитах подтверждено посредством исследования сегнетоэлектрической и магнитной петель гистерезиса, а также температурных зависимостей $\sigma(T)$ и $\varepsilon(T)$. При увеличении содержания магнитной фазы $\mathrm{NiFe}_{1.9} \mathrm{Co}_{0.02} \mathrm{O}_{4-\delta}$ в композитах диэлектрическая проницаемость, спонтанная и остаточная поляризации немонотонно уменьшаются. Наиболее существенные изменения свойств имеют место при низких концентрациях феррита (до $30 \mathrm{wt} . \%)$. Установлено, что при содержании
$\mathrm{NiFe}_{1.9} \mathrm{Co}_{0.02} \mathrm{O}_{4-\delta}$ менее $40 \mathrm{wt} \%$ диэлектрические потери в важном для практического применения диапазоне температур 20-80 $\mathrm{C}$ находятся на достаточно низком уровне $(\operatorname{tg} \delta \leq 0.05)$. Намагниченность насыщения $\sigma_{s}$ при комнатной температуре увеличивается пропорционально концентрации фазы феррита, соответственно, от $4 \mathrm{~A} \cdot \mathrm{m}^{2} \cdot \mathrm{kg}^{-1}$ при $x=0.1$ до $17 \mathrm{~A} \cdot \mathrm{m}^{2} \cdot \mathrm{kg}^{-1}$ при $x=0.4$.

Образцы с содержанием $\sim 40$ wt.\% $\mathrm{NiFe}_{1.9} \mathrm{Co}_{0.02} \mathrm{O}_{4-\delta}$ демонстрируют высокие МЭ-характеристики - продольный коэффициент по напряжению составляет $215 \mathrm{mV} / \mathrm{A}$ на частоте $1 \mathrm{kHz}$ и $130 \mathrm{~V} / \mathrm{A}$ на частоте электромеханического резонанса, равной $380 \mathrm{kHz}$.

\section{Список литературы}

[1] J. Ma, J. Hu, Z. Li, C.-W. Nan. Adv. Mater. 23, 1062 (2011).

[2] G. Srinivasan. Annu. Rev. Mater. Res. 40, 153 (2010).

[3] R.E. Newnham, D.P. Skinner, L.E. Cross. Mater. Res. Bull. 13, 525 (1978).

[4] R. Rani, P. Kumar, S. Singh, J.K. Juneja, K.K. Raina, C. Prakash. Integrated Ferroelectrics 122, 45 (2010).

[5] C.E. Ciomaga, M. Airimioaei, V. Nica, L.M. Hrib, O.F. Caltun, A.R. Iordan, C. Galassi, L. Mitoseriu, M.N. Palamaru. J. Eur. Ceram. Soc. 32, 3325 (2012).

[6] Y. Zhang, J.-P. Zhou, Q. Liu, S. Zhang, C.-Y. Deng. Ceramics Int. 40, 5853 (2014).

[7] J. Smit, H.P.J. Wijn. Ferrites. Philips Technical Library, Eindhoven (1959). 369 p.

[8] A.J. Moulson, J.M. Herbert. Electroceramics. Wiley, N.Y. (2003). 557 p.

[9] R.D. Shannon. Acta Cryst. A 32, 751 (1976).

[10] H. Yang, H. Wang, L. He, X. Yao. Mater. Chem. Phys. 134, 777 (2012).

[11] H. Zheng, W. Weng, G. Han, P. Du. J. Phys. Chem. C 117, 12966 (2013).

[12] L. Mitoseriu, V. Buscaglia. Phase Transitions 79, 1095 (2006).

[13] H. Zheng, L. Li, Z. Xu, W. Weng, G. Han, N. Ma, P. Du. J. Appl. Phys. 113, 044101 (2013).

[14] Z. Yu, C. Ang. J. Appl. Phys. 91, 794 (2002).

[15] В.М. Петров, М.И. Бичурин, G. Srinivasan. Письма в ЖТФ 30, 81 (2004).

[16] S.R. Kulkarni, C.M. Kanamadi, B.K. Chougule. Mater. Res. Bull. 40, 2064 (2005).

[17] J.V. Mantese, A.L. Micheli, D.F. Dungan, R.G. Geyer, J. BakerJarvis, J. Grosvenor. J. Appl. Phys. 79, 1655 (1996).

[18] R.-A. Eichel. J. Electroceram. 19, 9 (2007).

[19] D. Damjanovic. Rep. Prog. Phys. 61, 1267, (1998).

[20] В.Н. Шут, С.Р. Сырцов, В.Л. Трубловский. ФТТ 53, 1761 (2011).

[21] В.Н. Шут. ФТТ 55, 1339 (2013).

[22] J.-P. Zhou, L. Lv, Q. Liu, Y.-X. Zhang, P. Liu. Sci. Technol. Adv. Mater. 13, 045001 (2012).

[23] L. Lv, J.-P. Zhou, Q. Liu, G. Zhu, X.-Z. Chen, X.-B. Bian, P. Liu. Physica E 43, 1798 (2011).

[24] В.М. Петров, Д.С. Тусков, В.М. Лалетин, G. Srinivasan. Письма в ЖТФ 34, 83 (2008).

Редактор К.В. Емцев 